\title{
Value for money
}

\author{
2009 is turning out to be an interesting year for research funding in the UK. Everyone wants the best \\ science to be funded, but it's not clear that the proposed policy changes will achieve this.
}

In early 2009, an announcement made by the Engineering and Physical Sciences Research Council (EPSRC) sent a shockwave through the academic community: from April 2009, and to be applied retrospectively, the EPSRC would no longer consider resubmissions of rejected proposals and, more controversially, exclude "repeatedly unsuccessful applicants from submitting proposals for a period of twelve months"1. The policy will affect those who have three or more proposals rejected over a two-year period and a personal success rate of less than $25 \%$. The EPSRC say that they have introduced the policy to reduce the burden on those who referee the grant proposals; however, many academics are skeptical that it will achieve this aim.

\section{Great leaps in science do not occur by making small changes to existing concepts}

The reaction of researchers, which included a petition to government, forced the EPSRC to change the policy from 2010 those affected can submit one proposal within the 12-month 'exclusion period'. Nevertheless, the policy on resubmissions remains, and poses an important question: will the regulation curtail new avenues of thought? Researchers may shy away from more exploratory proposals in case failure prevents future applications for grants to extend established work.

Great leaps in science and their subsequent exploitation however, do not often occur by making small changes to existing concepts. What's more, any benefits to society that stem from the research are often not foreseeable or emerge quickly. Obviously scientists understand this, but it is not always clear that those who fund them appreciate the process. For example, it is known that $\mathrm{X}$-ray and magnetic resonance imaging stem from fundamental physics research. The question arises as to whether this research would have been funded within the current system, but more importantly, it demonstrates the need to keep supporting blue-sky research.
Currently, there is an ongoing debate as to how much the UK government is meddling with the science and research that it supports. The research councils have been asked to collectively generate $£ 106$ million of efficiency savings that will be put back into research. The Minister of State for Science and Innovation, Lord Drayson, asserted that the research councils themselves should decide how they do this ${ }^{2}$. Some savings will be made by lowering administration costs, but the government will accept most savings as a reshuffling of money from one area of research to another ${ }^{2}$. Alongside this, the Secretary of State for Innovation, Universities and Skills stated: "The councils will be developing plans...to refocus their research programmes...into new priority areas such as the green economy (and) life sciences"3. Bearing in mind that the research councils have to describe how they distribute their funds to the government, it would seem unwise for the research councils to 'save' money by directing funds away from these priority areas.

It is not obvious how the research councils will decide on which fields will benefit, but a new document required to form part of every proposal could help them. Research councils, including the EPSRC and the Natural Environment Research Council (NERC), now require an economic impact plan to be included in each application. The opportunity to mention any likely economic outcomes was already present, but the new plan makes a more formal presentation obligatory. How much it will influence whether or not a grant gets funded is hard to say as each research council answers this question differently. The plan gives groups who carry out applied research a chance to express this; however, it must not disadvantage those focusing on more basic aspects of science.

Materials research is in a better position than most areas - for many materials scientists it is relatively simple to imagine a route from their basic research to practical applications that can affect society. It is therefore easy for the government to justify spending on these areas. A danger is that if expectations are not met, questions will be asked, even if a whole new branch

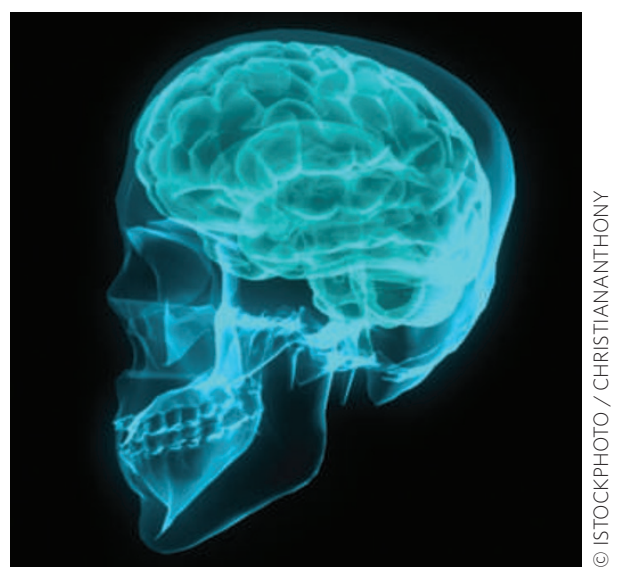

Advances in fundamental physics are responsible for developing $X$-ray imaging, illustrating that it is imperative to fund basic research.

of research has been discovered along the way. This could be perceived as lying to the tax-payer and ultimately worsen government and public perception.

The extent to which the UK government is influencing research directions however, is not necessarily the biggest concern. Over the course of several months in 2008, more than $80 \%$ of chemistry proposals originally proposed to be suitable for funding after peer-review were rejected at the next stage 4 . The 'extra' $£ 106$ million for the research councils is a small part of their $£ 4$ billion fund and will do little to improve this. Unfortunately in these challenging economic times, the government did little to increase the UK science budget in April, even though it lags behind the US and Japan in terms of spending on science as a percentage of GDP ${ }^{5}$. To reap the economic growth that the government believes science will provide 6 , instead of debating the details, a significant increase in overall levels of research funding is needed.

\footnotetext{
References

1. http://www.epsrc.ac.uk/CMSWeb/Downloads/Publications/ Connect/Connect\%2070.pdf

2. http://www.publications.parliament.uk/pa/cm200809/cmselect/ cmdius/uc169-ii/uc16902.htm

3. http://www.dius.gov.uk/about_DIUS/budget2009

4. http://gow.epsrc.ac.uk/GowDefault.aspx

5. http://www.dius.gov.uk/science/science_funding/set_stats

6. Nature Mater. 7, 511 (2008).
} 